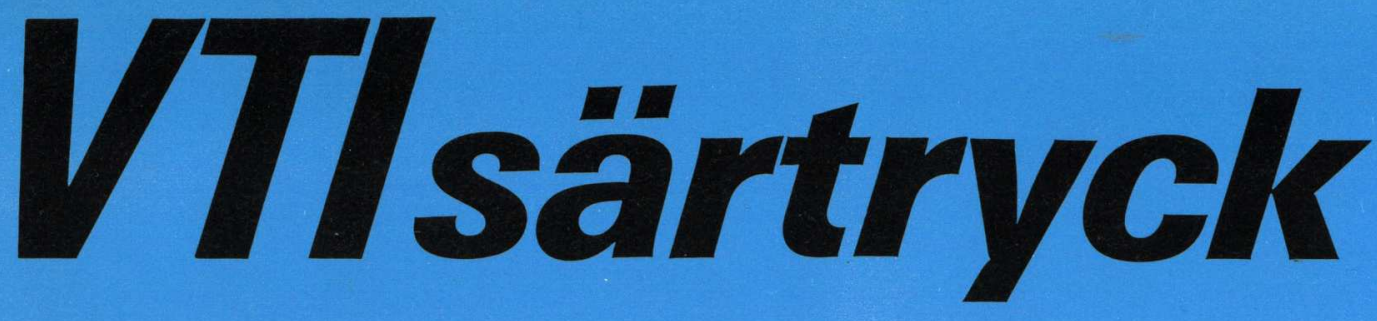

\title{
Driving Vigilance Simulator Test
}

Per-Olle Haraldsson and Christer Carenfelt, Departments of Otorhinolaryngology, Karolinska Hospital and Karolinska Institute, Stockholm, Sweden

Hans Laurell and Jan Törnros, Swedish Road and Traffic Research Institute, Linköping, Sweden

Reprint from Acta Otolaryngol (Stockholm) 1990; 110, pp 136-140 
$\ldots$ 


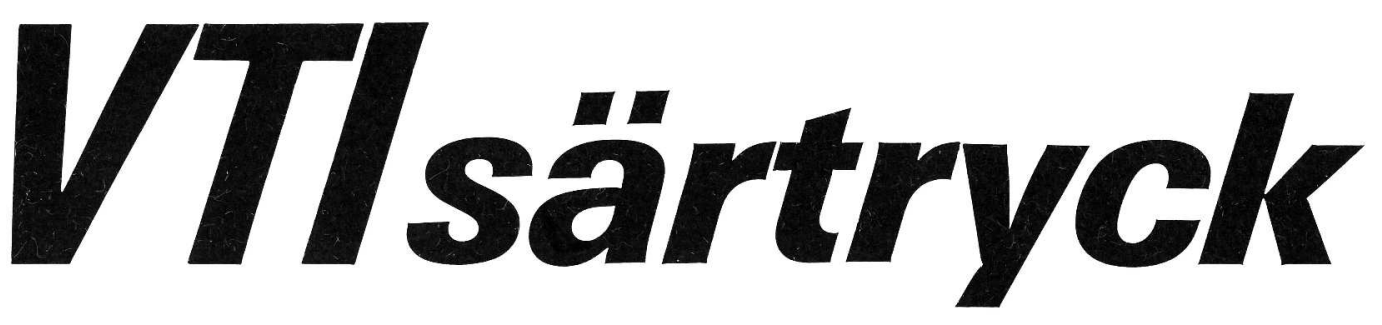

\section{Driving Vigilance Simulator Test}

Per-Olle Haraldsson and Christer Carenfelt, Departments of Otorhinolaryngology, Karolinska Hospital and Karolinska Institute, Stockholm, Sweden

Hans Laurell and Jan Törnros, Swedish Road and Traffic Research Institute, Linköping, Sweden

Reprint from Acta Otolaryngol (Stockholm) 1990; 110, pp 136-140 


\title{
Driving Vigilance Simulator Test
}

\author{
PER-OLLE HARALDSSON,${ }^{1}$ CHRISTER CARENFELT,${ }^{1}$ HANS LAURELL ${ }^{2}$ \\ and JAN TÖRNROS ${ }^{2}$
}

From the ${ }^{1}$ Departments of Otorhinolaryngology, Karolinska Hospital and Karolinska Institute, Stockholm and ${ }^{2}$ Swedish Road and Traffic Research Institute, Linköping, Sweden

Haraldsson P-O, Carenfelt C, Laurell H, Törnros J. Driving vigilance simulator test. Acta Otolaryngol (Stockh) 1990; 110: 136-140.

Drivers suffering from sleepiness at the wheel run the risk of being involved in car accidents. To evaluate whether objective data of driving performance can be assessed in patients with excessive tendency of falling asleep at the wheel, two test versions of a computerized driving program were created to fit an advanced driving simulator. For the evaluation 15 male drivers with habitual sleep spells whilst driving were selected among patients with the clinical features of the sleep apnoea syndrome. The brake reaction time and the deviations from straight road-line were significantly increased when compared to the performance of 10 matched controls. Irrespective of test version, the driving simulator with the program used was found to be a sensitive method to ascertain driving vigilance impairment in quantitative terms. It would also be a valuable method to evaluate the efficiency of treatment in selected patients. Key words: driving simulator test, automobile accidents, hypersomnia at the wheel, sleep apnoea syndrome.

\section{INTRODUCTION}

Drivers who suffer from hypersomnia at the wheel run the obvious risk of being involved in car accidents. At least fifteen more or less common sleep disorders may cause excessive diurnal hypersomnia (1). For patients with narcolepsy the relative risk of being involved in such accidents is twice as high as for sleep apnoea patients (2), but since the sleep apnoea syndrome is a more prevalent disorder, found in $1-3 \%$ of the middle-aged male population $(3,4)$, it is likely to be a major risk factor in the traffic. Patients with diurnal hypersomnia due to sleep apnoea perform poorly on cognitive testing in terms of thinking, perception, memory, communication and ability to perceive new information, thus potentially becoming distractible, confused and hostile. They also show psychomotor impairment, especially while undergoing tests that require a high level of attention and concentration (5-7). To assess driving vigilance among these patients, an appropriate driving test should be of value for risk identification.

As preliminarily reported $(8,9)$, a computerized driving program has been devised for an advanced driving simulator (10). The method is described and performance data given for patients with clinical symptoms of sleep apnoea syndrome, sleepy at the wheel.

\section{SUBJECTS AND METHODS}

\section{Selection of patients and control drivers}

To evaluate driving tasks designed for the simulator, 15 patients and 10 controls were selected. All subjects were men, aged 30-69 years (mean 54 vs. 55 years) with experience of regular car driving (average mileage per year: 28000 vs. $21000 \mathrm{~km}$ ). The patients complained of four recurring ("almost always or often") symptoms: heavy snoring, sleep disturbances, excessive daytime sleepiness and hypersomnia whilst driving. The controls 


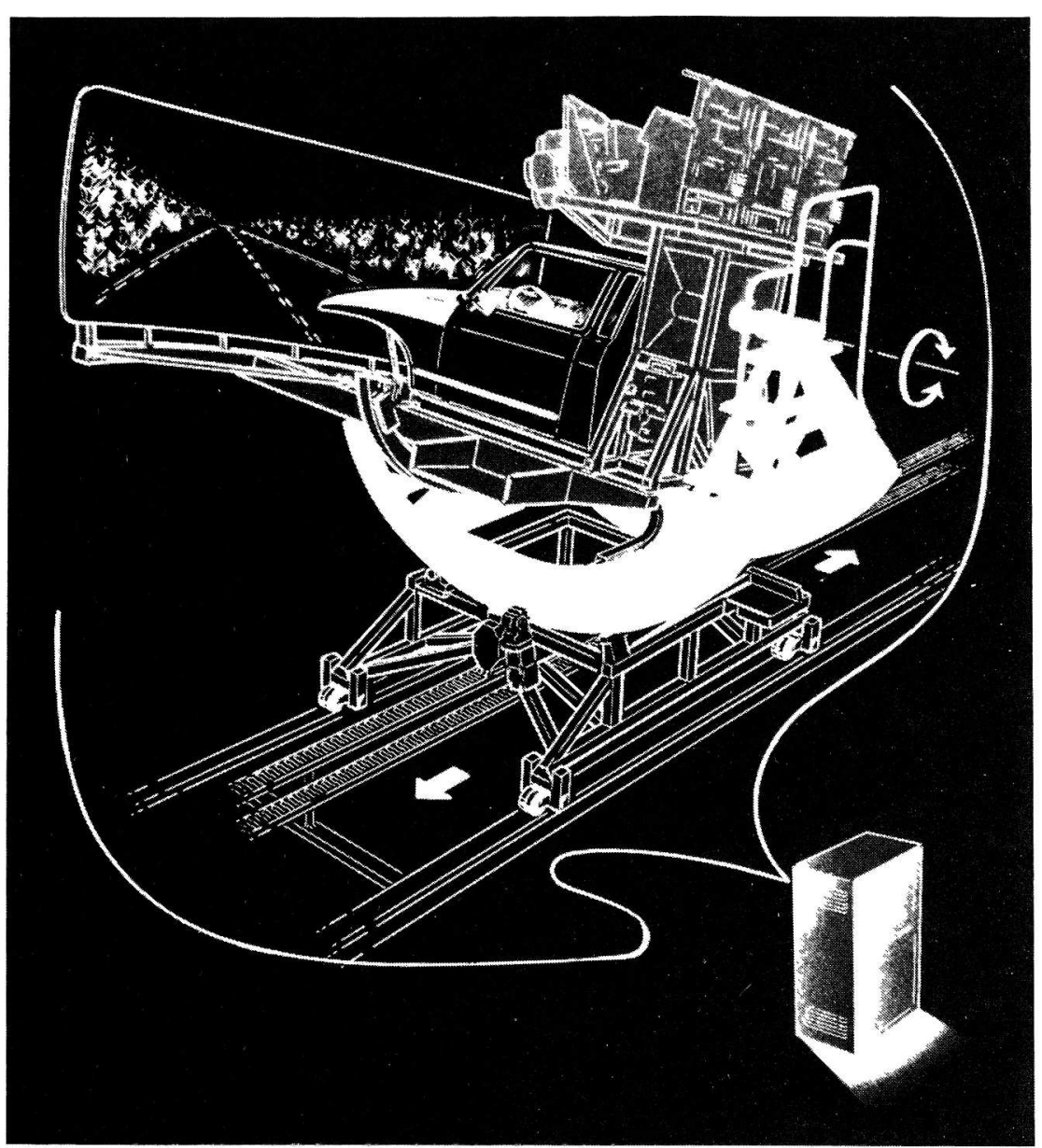

Fig. 1. Drawing demonstrating main features of the Swedish Road and Traffic Research Institute car driving simulator.

denied these symptoms, except for snoring in some cases. Occurrence of symptoms was scored by a questionnaire (11).

\section{Driving simulator}

The advanced Swedish Road and Traffic Research Institute driving simulator is mounted in the driver's cabin of a SAAB 900 (Fig. 1). A moving base system with four degrees of freedom of movement of the cabin created such forces as are normally felt during driving. The system is fully interactive, i.e. any action from the driver is fed into the computer which updates the visual presentation and creates the movement of the cabin and the momentum in the steering wheel. The visual system makes use of three colour TV projectors and gives a wide-angle picture. The road is created by specially developed digital electronics. The simulator is also equipped with a sound generating system to emulate engine and wind noises. Further technical details are given elsewhere (10).

A monotonous driving task intended to involve the effects of sleepiness was created. The subject was required to drive the vehicle at about $90 \mathrm{~km} / \mathrm{h}(55 \mathrm{mph})$ in a one-lane, narrow $(3.5 \mathrm{~m})$ curved road at twilight. During the drive, he had to react to light-stimuli seen through the front-window: a flickering $6 \mathrm{~Hz}$ quadratic stimuli (size corresponding to $\left.0.46^{\circ}\right)$ presented in five positions $\left(55^{\circ}, 40^{\circ}\right.$ and $15^{\circ}$ to the left and $25^{\circ}$ and $35^{\circ}$ to the right of the middle). The distribution in time and space was equally allocated, as was the distribution for the inter-stimulus intervals ( 1 to $81 \mathrm{sec}$, at an average of $40 \mathrm{sec}$ ). The stimuli were of two kinds, red/green requiring an immediate brake reaction, and yellow/black requiring the subject to press the signal button as fast as possible. The signal button stimuli-not used for evaluation of reaction times-appeared four times more often than brake reaction stimuli. This was the basic set of stimuli to which the drivers had to react (test A). Because 
of a technical error one patient and one control were given the instruction not to press the signal button. With the intention of refining the discrimination power, another test version was created by introducing an additional signal button stimulus which was trigged each time steering wheel movements were smaller than $1^{\circ}$ for $2 \mathrm{sec}$ (test B). This test was used in 5 of the patients and in 4 control drivers.

Three variables were analysed to assess driving performance, the brake reaction time (BRT), the lateral position deviation (LPD) from straight road-line, and the number of offroad episodes. For each driver the arithmetic mean and the 90th percentile (P90) of BRT were calculated, based on 25 stimuli per 90 min of driving. LPD was sampled twice per second and the standard deviation was calculated for each 5-min period. The test duration was not fixed, but the subjects were instructed to drive for a period of $90 \mathrm{~min}$. Performance data collected during that period were used for the analysis. During the test, the drivers were video-taped via infra-red sensitive television and observed sleep attacks were recorded.

The simulator test was preconditioned as follows: no alcohol ingestion was allowed and the test situation presupposed normal sleep the night before. No tiresome driving was permitted during the day of testing. Before the test drive, the subjects had to practise the driving task for $15 \mathrm{~min}$, after which luncheon was served. No coffee was ingested at that time and the trial started after another $10 \mathrm{~min}$ of adaptation. During the test, no conversation with the subjects was allowed.

\section{RESULTS}

During the driving test most of the patients did poorly. Although encouraged to drive for $90 \mathrm{~min}$, three of the patients gave up during the first hour of testing due to sleepiness, as demonstrated by the video-recordings. The average test period used to collect data therefore became shorter for the patients than for the controls, 77 and $87 \mathrm{~min}$, respectively. Six patients missed a total of 11 reaction stimuli, whereas none of the controls missed any of the stimuli. Eight of the patients drove off the road at least once, as compared to only one of the controls. The video-recordings of the drivers clearly showed that most of the sleepy drivers vigorously struggled to stay awake during their performance. In some cases the problem became evident within 10-15 min. Video-recordings of the patients also revealed many more instances of reduced attention or momentary episodes of sleep than the actual number of crashes reflects. Although all the sleepy drivers demonstrated such instances of sleep spells, only 8 drove off the road (Table I).

Irrespective of test version used, the driving program discriminated the driving performance of patients from that of controls (Table II). The results show that the patients, overall, had significantly increased reaction times and deviated more from the straight road-line than did control drivers. The average 90th percentile BRT of the sleepy drivers was $1.2 \mathrm{sec}$ longer than for control drivers, corresponding to an extra $30 \mathrm{~m}$ to stop at the current speed.

Table I. Results of test drive. Total off-road episodes and number of drivers involved

\begin{tabular}{lccc}
\hline & Patients $(n=15)$ & $p^{a}$ & Controls $(n=10)$ \\
\hline Mean test duration (min) & $77(30-90)$ & & $87(70-90)$ \\
Drivers off-road, $n$ & 8 & $<0.05$ & 1 \\
Total off-road episodes & $101(0-69)$ & 2 \\
\hline
\end{tabular}

${ }^{a}$ Fisher's exact probability test. 


\section{DISCUSSION}

This study describes a method by which driving performance objectively can be measured in drivers suffering from sleepiness at the wheel. Conventional vigilance tests are usually performed in front of a computer, where the time interval between a flash of light and pressing a button is recorded. These tests are found to be extremely sensitive for psychomotor depression (7), but do not simulate the conditions of car driving.

The driving simulator proved to be a sensitive tool to ascertain the degree of driving vigilance impairment. The discrimination power of the two test versions used would have been possible to compare by cross-over tests, but such a design was considered too inconvenient for the subjects. The driving task was found to be sufficiently monotonous and tiring to compromise the patients but not the controls. Thus, only one of the control drivers failed to stay on the road, while the majority of the patients crashed, at least once. Although the video recordings showed that most patients had recurrent sleep attacks, not all attacks led to accidents, especially since the short lapses frequently coincided with driving conditions not requiring any action from the driver. These results are most probably applicable even to real driving conditions $(2,11)$.

Sleepiness at the wheel is a common complaint in patients with the sleep apnoea syndrome. Amongst male drivers with main clinical features of the syndrome we found that $52 \%$ admitted habitual sleep spells at the wheel, but very few, less than $1 \%$, of age and sex-matched control drivers reported this problem (11). The total rate of car accidents was 2.8 times that of controls, but the rate of single-car accidents was even higher, almost 10 -fold that of controls. For patients with polysomnographically confirmed sleep apnoea, the rate of car accidents is similar. Findley et al. (12) found the total rate to be 2.6 times that of all drivers in the population studied.

\section{Table II. Driving performance of patients and controls}

Brake reaction time (BRT) and lateral position deviation (LPD) given as mean ( \pm SD) for the arithmetic means and for the 90th percentiles of two test versions (A: 10 patients and 6 controls, B: 5 patients and 4 controls)

\begin{tabular}{|c|c|c|c|}
\hline & \multicolumn{3}{|c|}{ Performance, mean $( \pm S D)$} \\
\hline & Patients & Controls & $t$-value ${ }^{a}$ \\
\hline \multicolumn{4}{|c|}{ Mean-BRT, sec } \\
\hline A & $1.61(0.20)$ & $1.37(0.17)$ & $2.36^{*}$ \\
\hline B & $2.40(0.67)$ & $1.22(0.24)$ & $3.31^{* *}$ \\
\hline All & $1.89(0.57)$ & $1.31(0.20)$ & $3.07 * *$ \\
\hline \multicolumn{4}{|c|}{ P90-BRT, sec } \\
\hline A & $2.32(0.37)$ & $1.69(0.24)$ & $3.63^{* *}$ \\
\hline $\mathrm{B}$ & $3.79(1.17)$ & $1.57(0.27)$ & $3.66^{* *}$ \\
\hline All & $2.85(1.02)$ & $1.65(0.25)$ & $3.62^{* * *}$ \\
\hline \multicolumn{4}{|c|}{ Mean-LPD, m. } \\
\hline A & $0.400(0.123)$ & $0.294(0.057)$ & $2.22 *$ \\
\hline $\mathrm{B}$ & $0.365(0.056)$ & $0.280(0.055)$ & $2.29^{*}$ \\
\hline All & $0.388(0.103)$ & $0.288(0.056)$ & $2.80^{* *}$ \\
\hline \multicolumn{4}{|c|}{ P90-LPD, m. } \\
\hline A & $0.503(0.184)$ & $0.331(0.052)$ & $2.22 *$ \\
\hline $\mathrm{B}$ & $0.433(0.111)$ & $0.315(0.052)$ & $1.94 *$ \\
\hline All & $0.478(0.16)$ & $0.324(0.052)$ & $2.91^{* *}$ \\
\hline
\end{tabular}

\footnotetext{
${ }^{a}$ Student's $t$-test (one-tailed). BRT not analysable in patient number 3 (test A), and LPD not
} analysable in patient number 6 (test A). 
The poor simulator driving performance of our patients is likely to be valid for all drivers recognizing themselves as sleepy at the wheel, irrespective of cause. However, the patients in the present study, suffering from clinical features of sleep apnoea syndrome, improved their driving performance when retested after uvulo-palatopharyngoplasty (13).

The driving simulator test seems to be a valuable method by which the efficiency of treatment of diurnal hypersomnia can objectively be measured.

\section{ACKNOWLEDGEMENTS}

This study was suppori ' by grants from Folksam Research Foundation, The Memorial Foundation of Sigurd and Elsa Golje, and from the Karolinska Institute.

\section{REFERENCES}

1. Roffward HP, et al. Association of sleep disorders centers, diagnostic classification of sleep and arousal disorders. Sleep 1979; 2: 1-137.

2. Aldrich M, Aldrich K, Kehn T. Automobile accidents: relatior - excessive daytime sleepiness. Abstracts from the 5th Intern Congress of Sleep Research. Copenhage., 1987: 399.

3. Gislason T, Almqvist M, Boman G, Eriksson G, Taube A. Prevalence of sleep apnoea syndrome among Swedish men-an epidemiological study. J Clin Epidemiol 1988; 41: 571-6.

4. Cirignotta F, D'Alessandro R, Partinen $\mathrm{M}$ et al. Prevalence of every night snoring and obstructive sleep apnoea among 30-69-year-old men in Bologna, Italy. Acta Psychiatr Scand 1989; 79: $366-72$.

5. Kales A, Caldwell AB, Cadieux RJ, et al. Severe obstructive sleep apnoea. II. Associated psychopathology and psychosocial consequences. J Chron Dis 1985; 38: 427-34.

6. Bonnet MH. Effects of sleep disruption, performance and mood. Sleep 1985; 8: 11-19.

7. Findley LJ, Barth JT, Powers DC. Cognitive impairment in patients with obstructive sleep apnoea and associated hypoxemia. Chest 1986; 90: 686-90.

8. Haraldsson P-O, Carenfelt C, Nygren Å, Laurell H, Persson H, Törnros J. Är sömnapnésyndromet en riskfaktor i trafiken? Swedish Otolaryngol Assoc 1988; 2: 38-39.

9. Haraldsson P-O, Carenfelt C, Laurell H, Nygren Å, Tingvall C, Törnros J. Driving performance and single-car accidents among drivers with symptoms of sleep apnoea syndrome. First World Conference on Accident and Injury Prevention. Abstracts, 1989: 409.

10. Törnros J, Jansson H, Laurell $\mathrm{H}$ et al. The VTI driving simulator-driver performance applications. Commission of European Communities, Workshop, Bremen 1988: 23.

11. Haraldsson P-O, Carenfelt C, Diedrichsen F, Nygren $\AA$, Tingvall C. Clinical symptoms of sleep apnoea syndrome and automobile accidents. ORL 1990; 52: 57-62.

12. Findley LJ, Unverzagt E, Suratt PM. Automobile accidents involving patients with obstructive sleep apnoea. Am Rev Respir Dis 1988; 138: 337-40.

13. Haraldsson P-O, Carenfelt C, Persson H, Sachs C, Törnros J. Simulated long-term driving performance before and after uvulopalatopharyngoplasty (unpublished).

Manuscript received October 4, 1989; accepted January 23, 1990

Address for correspondence: Christer Carenfelt, Department of Otorhinolaryngology, Karolinska Hospital, S-10401 Stockholm, Sweden 




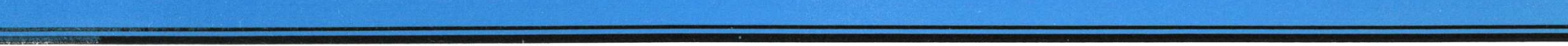

